JIIF (Jurnal Ilmu dan Inovasi Fisika)

Vol. 03, No. 01 (2019) 45 - 50

(C) Departemen Fisika FMIPA Universitas Padjadjaran

\title{
RANCANG BANGUN GASIFIKATOR DENGAN BAHAN BAKAR SEKAM PADI
}

\author{
OTONG NURHILAL*, SRI SURYANINGSIH, SETIANTO, DADAN HUSNI M. \\ Departemen Fisika, \\ Fakultas Matematika dan Ilmu Pengetahuan Alam, Universitas Padjadjaran \\ Jl. Raya Bandung-Sumedang Km 21, Jatinangor 45363 \\ *email : otong.nurhilal@phys.unpad.ac.id
}

\begin{abstract}
Abstrak. Telah dirancang gasifikator dengan diameter 13,97 cm dan tinggi 60,1 cm. Perancangan ini didasarkan pada asumsi kebutuhan energi sebesar 3,6 MJ, efisiensi $17 \%$ dan bahan bakar sekam padi dengan densitas $125 \mathrm{~kg} / \mathrm{m}^{3}$. Kinerja gasifikator ditentukan oleh parameter laju gasifikasi khusus dan hilang tekan. Berdasarkan hasil pengujian dari proses gasifikasi untuk $0,8 \mathrm{~kg}$ sekam padi dengan variasi suplai udara sebagai medium gasifikasi diperoleh nilai laju gasifikasi khusus terbesar sebesar $5,329 \mathrm{~kg} / \mathrm{m}^{2}$ jam dan nilai hilang tekan terkecil sebesar $565,293 \mathrm{~kg} / \mathrm{m} . \mathrm{s}^{2}$ pada tegangan blower 225 Volt.
\end{abstract}

Kata kunci : Gasifikasi, sekam padi, laju gasifikasi khusus, hilang tekan

\begin{abstract}
The gasifier has been designed with a diameter of $13.97 \mathrm{~cm}$ and a height of $60.1 \mathrm{~cm}$. This design is based on the assumption of an energy requirement of 3.6 MJ, an efficiency value of $17 \%$ and a rice husk fuel with a density of $125 \mathrm{~kg} / \mathrm{m}^{3}$. The performance of the gasifier is determined by two parameters, the specific gasification rate and the press lost. Based on the test results from the gasification process for $0.8 \mathrm{~kg}$ rice husk with variations in air supply as a gasification medium, the largest specific gasification rate value was obtained at $5.329 \mathrm{~kg} / \mathrm{m}^{2} \mathrm{~h}$ and the smallest press lost value was $565.293 \mathrm{~kg} / \mathrm{m}^{2}$ at 225 Volt blower voltage.
\end{abstract}

Keywords : Gasification, Rice Husk, Specific Gasification Rate, press lost

\section{Pendahuluan}

Teknologi potensial untuk pemanfaatan limbah biomassa salah satunya adalah gasifikasi. Gasifikasi merupakan proses termokimia untuk mengubah biomassa padat atau padatan berkarbon lainnya menjadi gas sintetik "seperti gas alam" yang mudah terbakar. Melalui proses gasifikasi, hampir semua bahan organik padat bisa diubah menjadi gas bakar yang bersih. Gas yang dihasilkan pada gasifikasi kandungannya didominasi oleh gas $\mathrm{CO}, \mathrm{H}_{2}$, dan $\mathrm{CH}_{4}$ [1].

Proses gasifikasi berlangsung di dalam suatu alat yang disebut gasifikator. Selama proses gasifikasi bahan bakar biomassa mengalami reaksi oksidasi parsial dengan udara, oksigen, dan uap air sebagai medium gasifikasinya.

Metode gasifikasi dinilai lebih menguntungkan seperti menghemat biaya sekitar $8 \%$ dan juga menghemat bahan bakar sekitar 12\% dibandingkan dibakar langsung [2]. Selain lebih mudah mengontrol laju dan suhu pembakaran, juga hasil pembakaran lebih bersih dan cenderung tidak menimbulkan efek merusak pada lingkungan. Gas

JIIF (Jurnal Ilmu dan Inovasi Fisika), ISSN: 2549-0516 
$\mathrm{CO}_{2}$ hasil pembakaran biomassa mudah terurai melalui proses fotosintesis pada tumbuhan. Bahan bakar biomassa juga sedikit mengandung unsur $\mathrm{S}$ dan $\mathrm{N}$ sehingga gas pembakaran mengandung sedikit emisi gas $\mathrm{SO}_{2}$ dan NOx [3]. Selain itu, kandungan $\mathrm{O}_{2}$ yang besar sekitar $45 \%$ mengurangi kebutuhan $\mathrm{O}_{2}$ untuk proses pembakaran [4].

Ada beberapa tipa gasifikator, salah satunya adalah tipe unggun tetap (fix bed). Tipe ini pada umumnya memerlukan energi berlebih karena adanya tumpukan padatan yang menyebabkan hilang tekan dan berpengaruh pada proses pengaliran reaktan yang berupa fluida. Kondisi ini mengharuskan pengumpanan biomassa ke dalam gasifikator memerlukan pengolahan awal seperti: pengeringan, pemotongan atau pemampatan.

Selain itu bentuk dan ukuran bahan bakar biomassa yang tidak seragam dapat menyebabkan kemacetan aliran bahan akan semakin besar yang selanjutnya akan berpengaruh pada tekanan dalam gasifikator serta aliran gas keluar. Dengan bentuk dan ukuran bahan bakar yang relatif seragam, kemacetan dapat dihindari.

Biomassa yang memiliki ukuran yang seragam diantaranya adalah sekam padi dengan ketebalan 0,1-0,2 mm, panjang 8-10 mm, lebar 2-3 mm, kadar air $16 \%$ dan densitas densitas sebesar $125 \mathrm{~kg} / \mathrm{m}^{3}$. Mengingat besarnya potensi energi sekam padi dan pentingnya penggunaan energi bersih, pada penelitian ini dilakukan rancang bangun gasifikasi sekam padi jenis gasifikator updraft dengan unggun tetap. Dipilihnya jenis ini karena memiliki efisiensi konversi karbon dan termal yang tinggi.

\section{Metode Penelitian}

\subsection{Perancangan Alat}

Gasifikator dibuat dari pelat besi dengan tebal $2 \mathrm{~mm}$ sebagai bahan utama sedangkan pada bagian dalam gasifikator dilapisi semen sebagai isolasi untuk menjaga suhu dalam gasifikator tidak terbuang ke lingkungan, lubang sebagai masukan udara blower dan keluaran gas produsen menggunakan pipa dengan ukuran 1 inci. Pada bagian bawah gasifikator dilengkapi dengan angsang (grate) berlubang sebagai penyaring abu sisa pembakaran. Wadah beridsi air ditempatkan pada bagian bawah gasifikator yang berfungsi untuk water seal sekaligus sebagai penampung abu dan arang sisa.

Perancangan gasifikator didasarkan pada asumsi kebutuhan energi $\left(Q_{n}\right)$ yang equivalen dengan produksi listrik $1 \mathrm{kWh}=3,6 \mathrm{MJ}$. Kebutuhan sekam padi (fuel consumption rate, FCR) untuk mensuplai kebutuhan energi dihitung dengan persamaan (1) [5]:

$$
F C R=\frac{Q_{n}}{C V \times \eta_{g}}
$$


dengan nilai kalor (CV) $12,5 \mathrm{MJ} / \mathrm{Kg}$ [6] dan $\eta_{g} 17 \%$ [7] . Diameter gasifikator (D) dihitung dengan persamaan (2) berikut [5]:

$$
D=\left(\frac{1,27 \times F C R}{S G R}\right)^{0,5}
$$

nilai SGR sekam padi $110-210 \mathrm{~kg} / \mathrm{m}^{2} / \mathrm{jam}$ [6]. Tinggi gasifikator $(\mathrm{H})$ dihitung dengan persamaan (3) berikut [5]:

$$
H=\frac{S G R \times t}{\rho_{B}}
$$

Hasil perhitungan parameter utama gasifikator adalah sebagai berikut.

Tabel 1. Parameter utama gasifikator

\begin{tabular}{cc}
\hline Parameter & Nilai \\
\hline FCR & $1,69 \mathrm{Kg} / \mathrm{jam}$ \\
$\mathrm{D}$ & $13,97 \mathrm{~cm}$ \\
$\mathrm{H}$ & $60,1 \mathrm{~cm}$ \\
\hline
\end{tabular}

Rancangan gasifikator yang telah dibuat dan model pengukuran hilang tekan seperti pada Gambar 1.

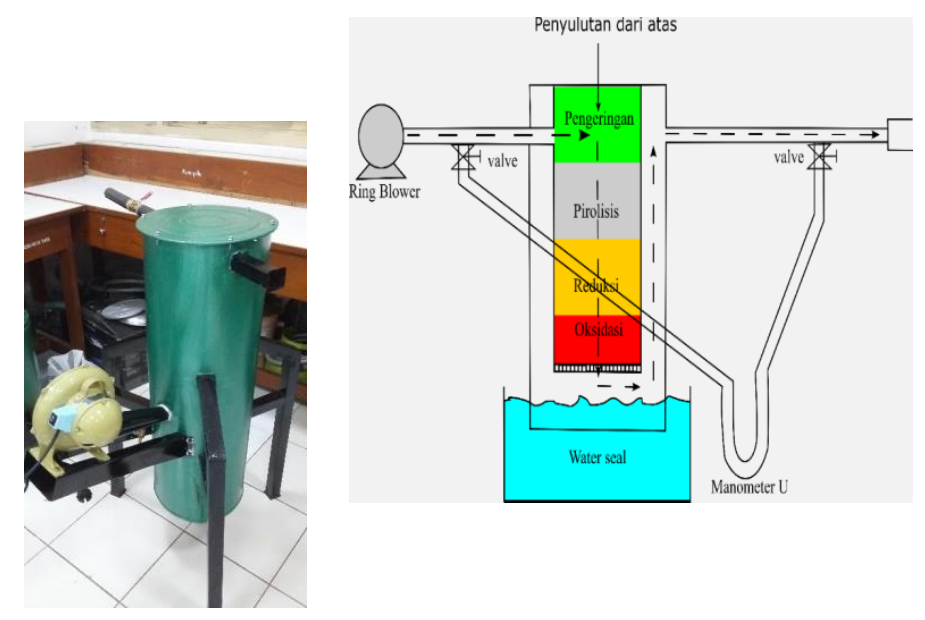

(a)

(b)

Gambar 1. (a) Gasifikator, (b) model pengukuran hilang tekan

\subsection{Tahapan Uji Kinerja Alat}

a. Proses gasifikasi

Bahan baku sekam padi ditimbang terlebih dahulu sebagai berat awal $\left(\mathrm{W}_{\mathrm{i}}\right)$. Di dalam gasifikator, sekam padi akan tergasifikasi dan gas produsen akan terbentuk dan masuk ke dalam anulus keluar melewati pipa keluaran gas. Gas produsen 
kemudian dibakar di dalam burner dengan cara di sulut dengan api dari luar. Laju aliran udara diatur dengn cara memvariasikan tegangan blower sehingga nyala api yang terbentuk lebih stabil. Lama waktu operasi dihitung sebagai $\left(\mathrm{t}_{\mathrm{op}}\right)$. setelah gasifikator dingin kemudian bahan bakar sisa dihitung sebagai berat akhir $\left(\mathrm{W}_{\mathrm{f}}\right)$.

b. Pengukuran temperatur gasifikasi

Pengukuran dilakukan dengan menggunakan termokopel yang di letakan di bagian pembakaran gasifikator. Pengukuran dilakukan dengan selang waktu 5 menit dengan masa bahan bakar $0,8 \mathrm{Kg}$ dengan variasi tegangan blower sebesar 125 volt, 150 volt, 175 volt, 200 volt, dan 225 volt.

c. Perhitungan spesific gasification rate (SGR) actual dan hilang tekan

SGR aktual didefinisikan sebagai kecepatan konsumsi biomassa per satuan luas penampang gasifikator. SGR dihitung dengan menggunakan persamaan berikut [6]:

$$
S G R=\frac{W_{i} \times W_{f}}{A_{g} \times t_{o p}}
$$

$A_{g}$ adalah luas penampang gasifikator bagian dalam. Perhitungan nilai hilang tekan menggunakan persamaan berikut [5]:

$$
\Delta p=\Delta h\left(\rho_{\text {air }}-\rho_{g}\right) g
$$

$(\Delta h)$ adalah pembacaan tinggi kolom cairan di dalam manometer pipa $U$ yang masing-masing ujungnya terpasang pada inlet dan outlet sistem seperti pada Gambar 1.b. Gambar 2 menunjukkan kondisi gasifikasi dari awal hingga terbentuk gas.

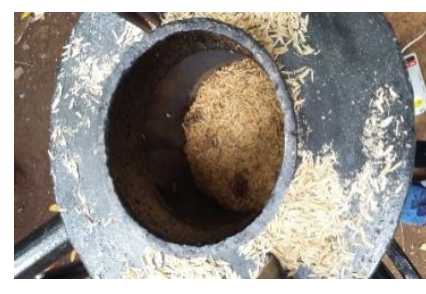

(a)

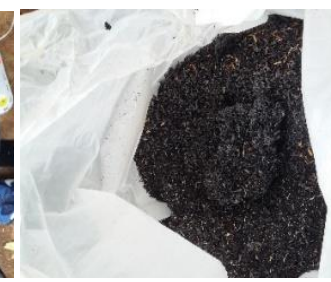

(b)

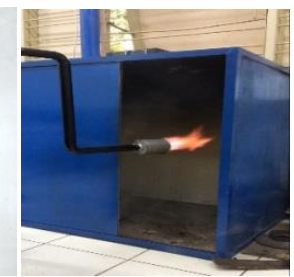

(c)

Gambar 2. Proses gasifikasi (a). Bahan bakar, (b). Rendemen hasil gasifikasi, (c), nyala api pada keluaran gas

\section{Hasil dan Pembahasan}

Hasil pengukuran temperatur selama proses gasfikasi untuk variasi tegangan blower ditunjukkan pada Gambar 3. 
Berdasarkan Gambar 3 terlihat bahwa semakin besar tegangan blower akan meningkatkan temperature dari proses pengeringan hingga gasifikasi. Hal ini disebabkan suplai udara kedalam gasifikator semakin banyak. Proses gasifikasi diperkirakan terjadi pada menit ke 20 dengan temperature diatas $600{ }^{\circ} \mathrm{C}$.

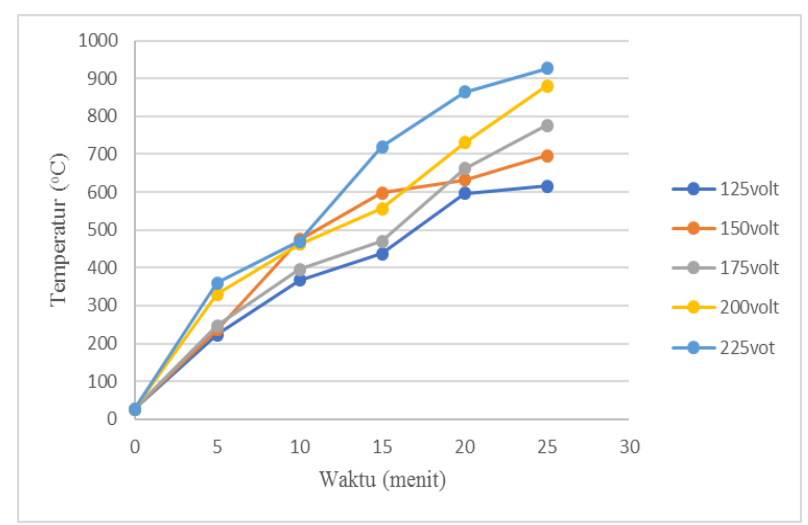

Gambar 3. Perubahan temperatur ruang pembakaran terhadap waktu dengan variasi tegangan blower

\subsection{Perhitungan SGR}

SGR dihitung dengan persamaan (4). Untuk menghitung SGR diperlukan data dimensi gasifikator, berat awal bahan bakar dan berat sisa bahan bakar, waktu operasi gasifikasi dan luas penampang gasifikator. Untuk diameter gasifikator $13,97 \mathrm{~cm}$ dan tinggi gasifikator $60,1 \mathrm{~cm}$ serta berat awal bahan bakar $0,85 \mathrm{~kg}$ dan berat sisa bahan bakar 0,196 kg dengan waktu operasi 25 menit diperoleh luas penampang gasifikator $0,295 \mathrm{~m}^{2}$ dan SGR $5,33 \mathrm{~kg} / \mathrm{m}^{2}$ jam. Nilai SGR aktual jauh lebih kecil dari nilai SGR asumsi. Hal ini menunjukkan kinerja gasifikator masih kurang bagus.

\subsection{Perhitungan hilang tekan}

Hilang tekan $\left(\Delta_{\mathrm{p}}\right)$ dihitung dengan persamaan (5) dengan $\rho_{\text {air }}=995,7 \mathrm{~kg} / \mathrm{m}^{3}, \rho_{g}=$ $1,166 \mathrm{~kg} / \mathrm{m}^{3}, g=9,8 \mathrm{~m} / \mathrm{s}^{2}$. Hasil perhitungan hilang tekan untuk semua variasi tegangan blower dicantumkan pada Table 3.

Tabel 3. Nilai hilang tekan pada variasi tegangan blower

\begin{tabular}{ccc}
\hline Tegangan Blower $(\mathrm{V})$ & $\Delta h(\mathrm{~m})$ & $\Delta p\left(\mathrm{~kg} / \mathrm{m} . \mathrm{s}^{2}\right)$ \\
\hline 125 & 0,072 & 701,74 \\
150 & 0,066 & 643,26 \\
175 & 0,064 & 623,77 \\
200 & 0,062 & 604,28 \\
225 & 0,058 & 565,29 \\
\hline
\end{tabular}

Berdasarkan Tabel 3 terlihat penurunan nilai hilang tekan seiring dengan kenaikan tegangan blower. Suplai udara yang semakin banyak mampu menurunkan tumpukan bahan bakar. 


\section{Kesimpulan}

Berdasarkan penelitian yang telah dilakukan maka dapat disimpulkan, gasifikator gasifikasi sekam padi sudah dapat dioperasikan dengan baik, namun stabilitas nyala api belum cukum stabil. Dimensi gasifikator gasifikasi yang telah di rancang, diameter (D) sebesar 13,97 cm, dan tinggi gasifikator $(\mathrm{H})$ sebesar $60,1 \mathrm{~cm}$. Nilai specific gasification rate (SGR) aktual sebesar $5,329 \mathrm{~kg} / \mathrm{m}^{2} \mathrm{jam}$. Nilai hilang tekan $\left(\Delta_{\mathrm{p}}\right)$ berkisar dari $701,743 \mathrm{~kg} / \mathrm{m} . \mathrm{s}^{2}$ hingga $565,293 \mathrm{~kg} / \mathrm{m} . \mathrm{s}^{2}$ untuk variasi tegangan dari 125-225 Volt.

\section{Daftar Pustaka}

1. A. Singh, N. K. Srivastava, V. Yadav, D. Kumar, Thermodynamic Study and Improving Efficiency of Biomass Gasifier. Advance Research in Electrical and Electronic Engineering (AREEE) Print ISSN : 2349-5804; Online ISSN : 23495812; Vol. 2 Issues 5 (2015) p. 47-51.

2. T. H. Jayah, L. Aye, R. J. Fuller, D.F. Stewart, Computer simulation of downdraft wood gasifier for tea drying. Journal of Biomass and Bioenergi, Vol 25 (2003) p. 459-469.

3. P. Mathieu, R. Dubuisson, (2002). Performance Analysis Of Biomass Gasifier. Journal of Energi Convertion and Management, Vol 43 (2002) p. 1291-1299.

4. M.J. Prins, K. J. Ptasinski, F. J. J.G. Janssen, From Coal to Biomass Gasification Comparison of Thermodyinamic Efficiency. Journal of Energi, Vol 32 (2007) p. $1248-1259$

5. A. W. Wusana, S. H. Pranolo, G. Noorachadi, L. Ratna, Perancangan Dan Uji-Kinerja Reaktor Gasifikasi Sekala Kecil. Surakarta: jurnal UNS. Vol. 9 No. 1 (2010) p. 29-33.

6. Belonio, T. Alexis, Rice Husk Gas Stove Handbook. Philipphins: Central Philippine University (2005).

7. Y. Yuliah, S. Suryaningsih, K. Ulfi, Penentuan Kadar Air Hilang dan volatile Matter pada Bio-Briket dari Campuran Arang Sekam Padi dan Batok Kelapa, Jurnal Ilmu dan Inovasi Fisika Vol. 01 No. 01 (2017) p.51-57.

8. Ismail, M. Urbanus, H. Murage, Ochieng Francis. Conversion of Rice Husks into an Energy Source through Gasification Technology Onchoke. International Journal of Science and Research (IJSR) Volume 5 Issue 9 (2016) p.1264-1268 